\title{
Ticks and associated pathogens collected from dogs and cats in Belgium
}

\author{
Edwin Claerebout ${ }^{*}$, Bertrand Losson ${ }^{2}$, Christel Cochez ${ }^{3}$, Stijn Casaert ${ }^{1}$, Anne-Catherine Dalemans ${ }^{4}$, Ann De Cat $^{1}$, \\ Maxime Madder ${ }^{5,6}$, Claude Saegerman $^{7}$, Paul Heyman $^{3}$ and Laetitia Lempereur ${ }^{7}$
}

\begin{abstract}
Background: Although Ixodes spp. are the most common ticks in North-Western Europe, recent reports indicated an expanding geographical distribution of Dermacentor reticulatus in Western Europe. Recently, the establishment of a D. reticulatus population in Belgium was described. D. reticulatus is an important vector of canine and equine babesiosis and can transmit several Rickettsia species, Coxiella burnetii and tick-borne encephalitis virus (TBEV), whilst Ixodes spp. are vectors of pathogens causing babesiosis, borreliosis, anaplasmosis, rickettsiosis and TBEV.

Methods: A survey was conducted in 2008-2009 to investigate the presence of different tick species and associated pathogens on dogs and cats in Belgium. Ticks were collected from dogs and cats in 75 veterinary practices, selected by stratified randomization. All collected ticks were morphologically determined and analysed for the presence of Babesia spp., Borrelia spp., Anaplasma phagocytophilum and Rickettsia DNA.

Results: In total 2373 ticks were collected from 647 dogs and 506 cats. Ixodes ricinus (76.4\%) and I. hexagonus (22.6\%) were the predominant species. Rhipicephalus sanguineus (0.3\%) and D. reticulatus (0.8\%) were found in low numbers on dogs only. All dogs infested with $R$. sanguineus had a recent travel history, but $D$. reticulatus were collected from a dog without a history of travelling abroad. Of the collected Ixodes ticks, 19.5\% were positive for A. phagocytophilum and $10.1 \%$ for Borrelia spp. (B. afzelii, B. garinii, B. burgdorferi s.s., B. lusitaniae, B. valaisiana and B. spielmanii). Rickettsia helvetica was found in $14.1 \%$ of Ixodes ticks. All Dermacentor ticks were negative for all the investigated pathogens, but one $R$. sanguineus tick was positive for Rickettsia massiliae.
\end{abstract}

Conclusion: D. reticulatus was confirmed to be present as an indigenous parasite in Belgium. B. lusitaniae and $R$. helvetica were detected in ticks in Belgium for the first time.

Keywords: Ticks, Dermacentor reticulatus, Dogs, Cats, Belgium, Borrelia, Anaplasma, Rickettsia

\section{Background}

The most common tick in North-Western Europe is the sheep or castor bean tick, Ixodes ricinus. This tick species is also widely distributed in Belgium [1]. Ixodes ticks are vectors of a broad range of pathogens of medical and veterinary importance, such as Babesia spp., Borrelia spp., Anaplasma phagocytophilum, Rickettsia spp., Bartonella spp. and tick-borne encephalitis virus (TBEV). The brown dog tick, Rhipicephalus sanguineus and the European meadow tick, Dermacentor reticulatus are occasionally introduced into Northern Europe with imported dogs or

\footnotetext{
* Correspondence: edwin.claerebout@ugent.be

'Laboratory of Parasitology, Faculty of Veterinary Medicine, Ghent University, Merelbeke, Belgium

Full list of author information is available at the end of the article
}

by dogs travelling from endemic areas. $R$. sanguineus is a vector of, among others, Babesia vogeli, Ehrlichia canis, Hepatozoon canis, Rickettsia conorii and Cercopithifilaria spp. D. reticulatus is an important vector of canine and equine babesiosis and can transmit Rickettsia spp., Francisella tularensis, Coxiella burnetii and TBEV. Until recently, the French-Belgian border was considered to be the northern boundary of the distribution of $D$. reticulatus in Western Europe [2]. However, recent reports indicated that the habitat of D. reticulatus is expanding in NorthWestern Europe, with several foci now present in The Netherlands [3] and in Germany [4]. The occurrence of autochthonous cases of canine babesiosis in Belgium during the last two decades [5] suggests that this tick species could also be indigenous in this country. Low

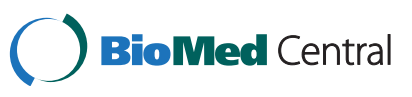


numbers of $D$. reticulatus were previously found on dogs in Belgium (Losson et al., personal communications), but it was not clear whether these ticks belonged to indigenous tick populations or were imported after travelling abroad and the presence of tick-borne pathogens in these ticks was not investigated. Therefore, a new survey was conducted in 2008-2009 to investigate the presence of different tick species collected from dogs and cats in Belgium and their associated pathogens. Dogs and cats were chosen, because several tick-borne diseases are of clinical importance in dogs and/or cats (e.g. babesiosis and ehrlichiosis) and because dogs and cats live in the close vicinity of their owners and can act as direct sentinels for infection of humans [6]. The approach of gathering data on the distribution of (zoonotic) vector-borne diseases through a veterinary survey is consistent with the 'One Health' concept $[7,8]$. Based on the recurrent collection of $D$. reticulatus ticks from a dog in this study, the presence of an indigenous $D$. reticulatus population in Belgium was confirmed by flagging at the study site [9].

\section{Methods}

\section{Tick collection}

A nationwide survey was performed in Belgium from April 2008 to April 2009. For each of the 25 veterinary districts, 3 companion animal practices were selected by stratified randomization (Figure 1). Ticks from cats and dogs, randomly submitted to seventy-five veterinary practices, were collected and preserved in $80 \%$ alcohol. For each animal enrolled in the study, information was recorded by the veterinarian about location, date of collection, animal description (dog/cat, age, sex, breed), the location on the host where the tick was found, whether the animal had travelled outside Belgium during the previous 2 weeks and whether the animal showed clinical signs that could be associated with a tick-borne disease, such as fever, apathy, anorexia, arthritis, anaemia or meningitis. The ticks were identified to species level, with stage and sex recorded, using a standard morphological key [10]. When D. reticulatus ticks were found on an animal without history of travel to a country known to be endemic for this tick species, the veterinarian or the owner was contacted for more information regarding the area in Belgium where the animal might have acquired the tick. These areas were subsequently surveyed for the presence of $D$. reticulatus by flagging the vegetation with a flannel cloth [9].

\section{DNA extraction, PCR amplification and sequencing}

One tick (nymph or adult) per animal was selected for DNA analyses, but when several tick species were present on a given animal, one tick of each species was randomly selected for further analysis. Tick DNA extraction was performed using a protocol with proteinase $K$ [11]. In order to detect false negative results due to PCR inhibition and to validate the efficiency of the DNA extraction, a PCR targeting a $325 \mathrm{bp}$ DNA fragment corresponding to the tick $16 \mathrm{~S}$ rRNA gene was included, using $16 \mathrm{~S}+1$ and $16 \mathrm{~S}-2$ primers [12].

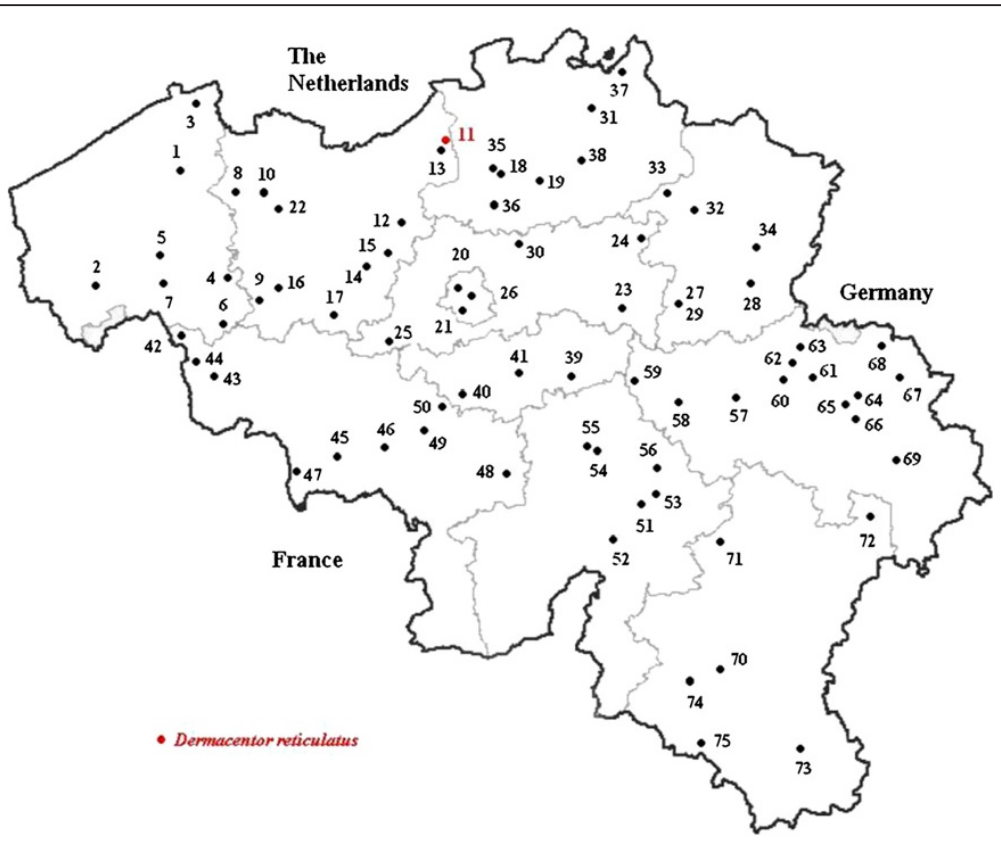

Figure 1 Distribution of selected veterinary practices and presence of an indigenous Dermacentor reticulatus population (red dot) in Belgium. 
The presence of Babesia spp., B. burgdorferi s.l., A. phagocytophilum and Rickettsia spp. DNA in tick DNA extracts was tested by PCR using specific primers for each pathogen. The primer sets and PCR conditions used for the different pathogens are listed in Table 1. A Babesia spp. specific PCR was based on the amplification of a 411$452 \mathrm{bp}$ fragment of the multicopy $18 \mathrm{~S}$ rRNA gene [13]. For the detection of $A$. phagocytophilum, a real-time PCR was performed according to [14], to amplify a 77-bp segment at the conserved amino-terminal coding region of the msp 2 gene. All samples, a negative and a positive control were run in duplicate, and samples with a $C \mathrm{p}$ (crossing point of the amplification curve) above 35 cycles were considered negative. For Borrelia spp. a specific nested PCR was developed targeting the flagellin gene, resulting in a $193 \mathrm{bp}$ fragment. The first reaction was carried out in a $25 \mu \mathrm{l}$ volume containing $0.2 \mu \mathrm{M}$ of each dNTP, $0.2 \mu \mathrm{M}$ of each primer, $1.5 \mathrm{mM} \mathrm{MgCl}_{2}, 5 \mu \mathrm{l}$ of $5 \times$ buffer, $0.625 \mathrm{U}$ of Taq and $2.5 \mu \mathrm{l}$ of the DNA extract. The second reaction was conducted on $2.5 \mu \mathrm{l}$ of a $1 / 10$ dilution of the first PCR product and contained in $25 \mu \mathrm{l} 0.2 \mu \mathrm{M}$ of each dNTP, $0.2 \mu \mathrm{M}$ of each primer, $1.5 \mathrm{mM} \mathrm{MgCl}_{2}, 5 \mu \mathrm{l}$ of $5 \times$ buffer and $0.625 \mathrm{U}$ of Taq. Plasmids containing genomic DNA of Borrelia spp. were kindly provided by F. Jongejan (Utrecht University, The Netherlands) and $H$. Sprong (RIVM, The Netherlands). DNA from Rickettsia spp. was detected using the rapidSTRIPE Rickettsia Assay (Analytik Jena, Jena, Germany), following the manufacturer's instructions. Positive samples were confirmed by PCR, targeting the citrate synthase gene ( lt $A$ ) with the Rsfg877/Rsfg1258 primers, which results in amplification of a $380 \mathrm{bp}$ fragment [15].

Tick DNA samples positive for Babesia spp. were sequenced as described by [13]. Samples that were positive for A. phagocytophilum were sent to GATC Biotech AB (Konstanz, Germany) for sequence analysis. Borrelia and Rickettsia PCR products were purified using the Qiaquick ${ }^{\circledR}$ purification kit (Qiagen) and fully sequenced in both directions using the Big Dye Terminator V3.1 Cycle sequencing Kit (Applied Biosystems). Sequencing reactions were analysed on a 3100 Genetic Analyzer (Applied Biosystems) and assembled with Seqman II (DNASTAR, Madison WI, USA). Sequences were compared with reference sequences by BLAST-analysis against the NCBI database.

\section{Statistical analysis}

Pathogen infection rates and 95\% confidence intervals were calculated for each pathogen.

The $\chi^{2}$-test was used to compare infection rates of pathogens between $I$. ricinus and I. hexagonus ticks, to compare infection rates for the different pathogens in ticks collected from dogs and cats with or without clinical signs indicative for tick-borne disease and to compare tick infection rates between northern Belgium (Flanders) and southern Belgium (Wallonia). A p-value of 0.05 was considered statistically significant.

\section{Results}

\section{Tick identification}

A total of 2373 ticks were collected from 647 dogs and 506 cats. The number of ticks per animal ranged from 1 to 34 , but most submissions $(70 \%)$ only contained a single tick. Most of the collected ticks were Ixodes spp. In cats, $I$. ricinus (80.1\% of infested cats, 95\% CI: 77.0-83.9) and $I$. hexagonus (23.4\%, 95\% CI: 19.9-27.3) were the only tick species found. The most frequently found tick species in dogs was also $I$. ricinus (82.1\% of infested dogs, $95 \%$ CI: 78.9-84.9), followed by I. hexagonus (18.9\%, 95\% CI: 15.9-22.2). Ticks were submitted throughout the year. Most $I$. ricinus ticks were collected during springtime, with a peak in May 2008 (843 ticks,). Most I. hexagonus were also recorded during this period, but a second, smaller peak occurred in October 2008. The majority of the ticks that were collected from dogs, were located on the head (42.7\%), the neck (21.7\%) and the thorax/abdomen $(22.6 \%)$. In cats, most ticks were recovered from the head $(40.9 \%)$ and the neck (41.6\%). The majority of the recovered ticks were adults (89.2\%), only $8.3 \%$ were nymphs and $2.6 \%$ larvae.

$R$. sanguineus and D. reticulatus were only found on 4 and 6 dogs, respectively. All dogs infested with $R$. sanguineus and 5 out of 6 dogs infested with $D$. reticulatus had a recent travel history (to France, Italy or an unspecified country), but $D$. reticulatus ticks were repeatedly collected from one dog without a history of travelling abroad. The presence of an indigenous population of $D$. reticulatus was confirmed by flagging the area where this dog was regularly taken for a walk (Beveren-Waas, Flanders, 51 $12^{\prime} 02^{\prime \prime} \mathrm{N}$, $4^{\circ} 14 ’ 15 ”$ 'E) (Figure 1) [9].

\section{Pathogen detection}

Of the collected Ixodes ticks, 1.3\% (95\% CI: 0.7-2.3) were found positive for Babesia spp. These results were described in detail by [13]. In addition, 19.5\% (95\% CI: 16.9-22.2) Ixodes ticks were positive for A. phagocytophilum and 10.2\% (95\% CI: 8.4-12.3) for Borrelia spp. B. afzelii (4.8\%, EMBL accession numbers HF930599 HF930641), B. garinii (1.8\%, EMBL accession numbers HF930648 - HF930672), B. burgdorferi s.s. (0.6\%, EMBL accession numbers HF930706 - HF930716), B. valaisiana (0.5\%, EMBL accession numbers HF930642 - HF930647), B. lusitaniae (2.1\%, EMBL accession numbers HF930682 HF930705) and B. spielmanii (0.7\%, EMBL accession numbers HF930673 - HF930681) were detected. R. helvetica was found in 14.1\% (95\% CI: 12.0-16.5) of Ixodes ticks (EMBL accession numbers HF930717 - HF930723). Infections with more than one pathogen occurred in 54 Ixodes ticks, most of them were infected with 2 
Table 1 Primers and polymerase chain reaction conditions for detection of pathogens in Ixodes, $R$. sanguineus and $D$. reticulatus

\begin{tabular}{|c|c|c|c|c|c|}
\hline Organism detected & Target gene & Primer sequences $\left(5^{\prime}-3^{\prime}\right)$ & Product $t$ size (bp) & Melting temperature & Reference \\
\hline \multirow[t]{6}{*}{ Borrelia burgdorferi s.l. } & \multirow[t]{6}{*}{ Flagellin } & Outer primers: & \multirow[t]{3}{*}{236} & - Denaturation $95^{\circ} \mathrm{C} 10 \mathrm{~min}$ & \multirow[t]{3}{*}{ / } \\
\hline & & Bflag2F: GCT GAA GAR CTT GGA ATG CAR CC & & - Hybridisation 35 cycles: $95^{\circ} \mathrm{C} 30 \mathrm{~s}, 59^{\circ} \mathrm{C} 30 \mathrm{~s}, 72^{\circ} \mathrm{C} 30 \mathrm{~s}$ & \\
\hline & & Bflag2R: AGC AGG YGY TGG YTG YTG AGC & & - Extension $72^{\circ} \mathrm{C} 10 \mathrm{~min}$ & \\
\hline & & Inner primers: & \multirow[t]{3}{*}{193} & - Denaturation $95^{\circ} \mathrm{C} 10 \mathrm{~min}$ & \multirow[t]{3}{*}{ / } \\
\hline & & Bflag2nestF: CWC CAG CRT CAC TाT CAG GR & & - Hybridisation 35 cycles: $95^{\circ} \mathrm{C} 30 \mathrm{~s}, 56^{\circ} \mathrm{C} 30 \mathrm{~s}, 72^{\circ} \mathrm{C} 30 \mathrm{~s}$ & \\
\hline & & Bflag2nestR: GYT GGY TGY TGA GCT CCT TC & & - Extension $72^{\circ} \mathrm{C} 10 \mathrm{~min}$ & \\
\hline \multirow{3}{*}{$\begin{array}{l}\text { Anaplasma } \\
\text { phagocytophilum }\end{array}$} & \multirow{3}{*}{$\begin{array}{l}\text { Major surface protein } \\
2 \text { (msp2) }\end{array}$} & Apmsp2f: ATG GAA GGT AGT GTT GGT TAT GGT ATT & \multirow[t]{3}{*}{77} & - Denaturation $95^{\circ} \mathrm{C} 10 \mathrm{~min}$ & \multirow[t]{3}{*}{ Courtney et al., 2004} \\
\hline & & \multirow[t]{2}{*}{ Apmsp2r TTG GTC TTG AAG CGC TCG TA } & & - Hybridisation 40 cycles: $95^{\circ} \mathrm{C} 15 \mathrm{~s}, 60^{\circ} \mathrm{C} 1 \mathrm{~min}$ & \\
\hline & & & & - Extension $60^{\circ} \mathrm{C} 1 \mathrm{~min}$ & \\
\hline \multirow[t]{4}{*}{ Rickettsia spp. } & \multirow[t]{4}{*}{ Citrate synthase $(g / t A)$} & Rsfg877: GGG GGC CTG CTC ACG GCG G & \multirow[t]{4}{*}{380} & - Denaturation $95^{\circ} \mathrm{C} 10 \mathrm{~min}$ & \multirow[t]{4}{*}{ Reis et al., 2011} \\
\hline & & \multirow[t]{3}{*}{ Rsfg1258: ATT GCA AAA AGT ACA GTG AAC A } & & - Hybridisation 5 cycles: $95^{\circ} \mathrm{C} 60 \mathrm{~s}, 58^{\circ} \mathrm{C} 60 \mathrm{~s}, 72^{\circ} \mathrm{C} 60 \mathrm{~s}$ & \\
\hline & & & & 35 cycles: $95^{\circ} \mathrm{C} 60 \mathrm{~s}, 51^{\circ} \mathrm{C} 60 \mathrm{~s}, 72^{\circ} \mathrm{C} 60 \mathrm{~s}$ & \\
\hline & & & & - Extension $72^{\circ} \mathrm{C} 10 \mathrm{~min}$ & \\
\hline \multirow[t]{3}{*}{ Babesia spp. } & \multirow[t]{3}{*}{$18 \mathrm{~S}$ rRNA } & BJ1:GTC TTG TAA TTG GAA TGA TGG & \multirow[t]{3}{*}{$411-452$} & - Denaturation $94^{\circ} \mathrm{C} 10 \mathrm{~min}$ & \multirow[t]{3}{*}{ Casati et al, 2006} \\
\hline & & \multirow[t]{2}{*}{ BN2:TAG TाT ATG GTT AGG ACT ACG } & & - Hybridisation: 35 cycles $94^{\circ} \mathrm{C} 1 \mathrm{~min}, 55^{\circ} \mathrm{C} 1 \mathrm{~min}, 72^{\circ} 2 \mathrm{~min}$ & \\
\hline & & & & - Extension $72^{\circ} \mathrm{C} 5 \mathrm{~min}$ & \\
\hline
\end{tabular}


pathogens $(\mathrm{n}=50)$. The most common co-infections were $A$. phagocytophilum with $R$. helvetica $(\mathrm{n}=18)$ and A. phagocytophilum with $B$. afzelii $(\mathrm{n}=11)$. Ticks positive for the investigated pathogens were detected across the entire country, but significantly more ticks were positive for Borrelia ( $\chi^{2}=19.49$, d.f. $\left.=1, \mathrm{P}<0.0001\right), A$. phagocytophilum ( $\chi^{2}=19.68$, d.f. $\left.=1, \mathrm{P}<0.0001\right)$ and $R$. helvetica ( $\chi^{2}=20.29$, d.f. $\left.=1, P<0.0001\right)$ in the northern part of Belgium (Flanders) compared to the southern part (Wallonia). Figures 2, 3, 4 show the numbers of ticks submitted per municipality and the percentage of ticks positive for Borrelia spp. (Figure 2), A. phagocytophilum (Figure 3 ) and R. helvetica (Figure 4).

Although B. burgdorferi s.l. was detected more frequently in $I$. ricinus (11.1\%) than in I. hexagonus $(6.9 \%)$, there was no significant difference between $I$. ricinus and I. hexagonus in the proportion of ticks that contained DNA from B. burgdorferi s.l. $\left(\chi^{2}=3.19\right.$, d.f. $\left.=1, \mathrm{P}=0.07\right)$, A. phagocytophilum $\left(\mathrm{X}^{2}=0.40\right.$, d.f. $\left.=1, \mathrm{P}=0.52\right)$ or $R$. helvetica ( $2=0.69$, d.f. $=1, \mathrm{P}=0.41$ ) (Table 2 ).

All Dermacentor ticks were negative for all the investigated pathogens, but one $R$. sanguineus tick was found positive for Rickettsia massiliae (EMBL accession number HF930724).

Most of the animals were healthy at the time of tick collection. Nevertheless, one cat showed swelling and pain at the site where a Borrelia- positive tick was attached. One cat and five dogs that were infested with ticks that

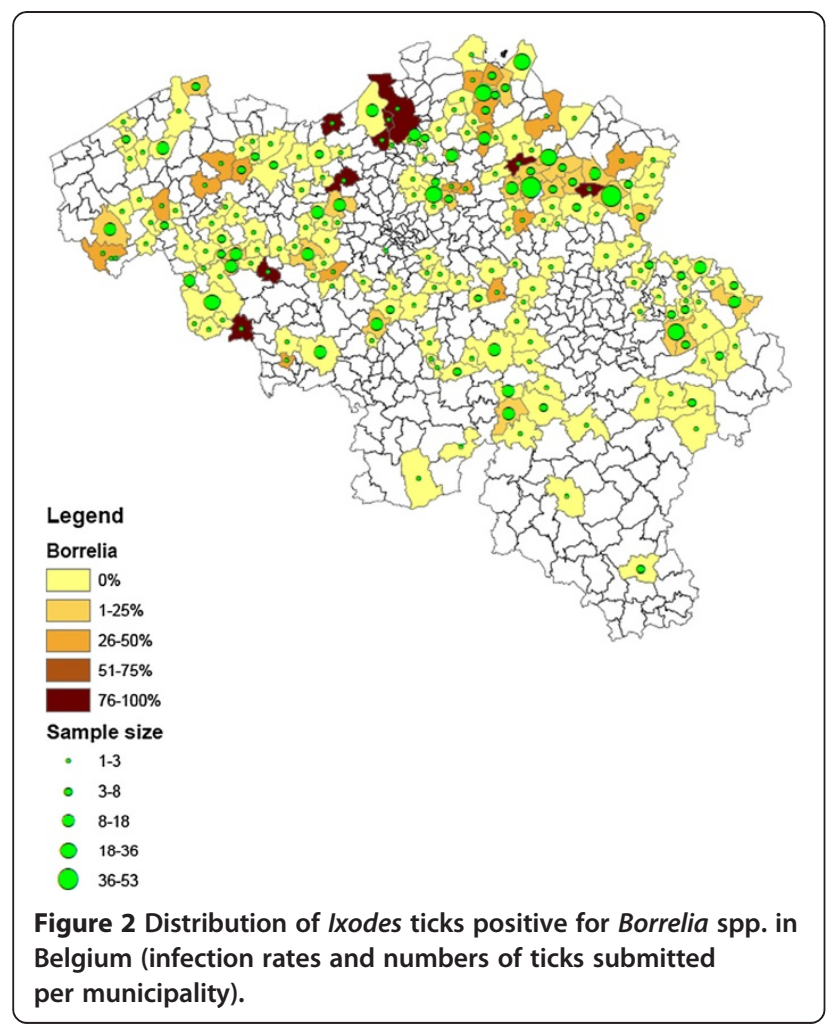

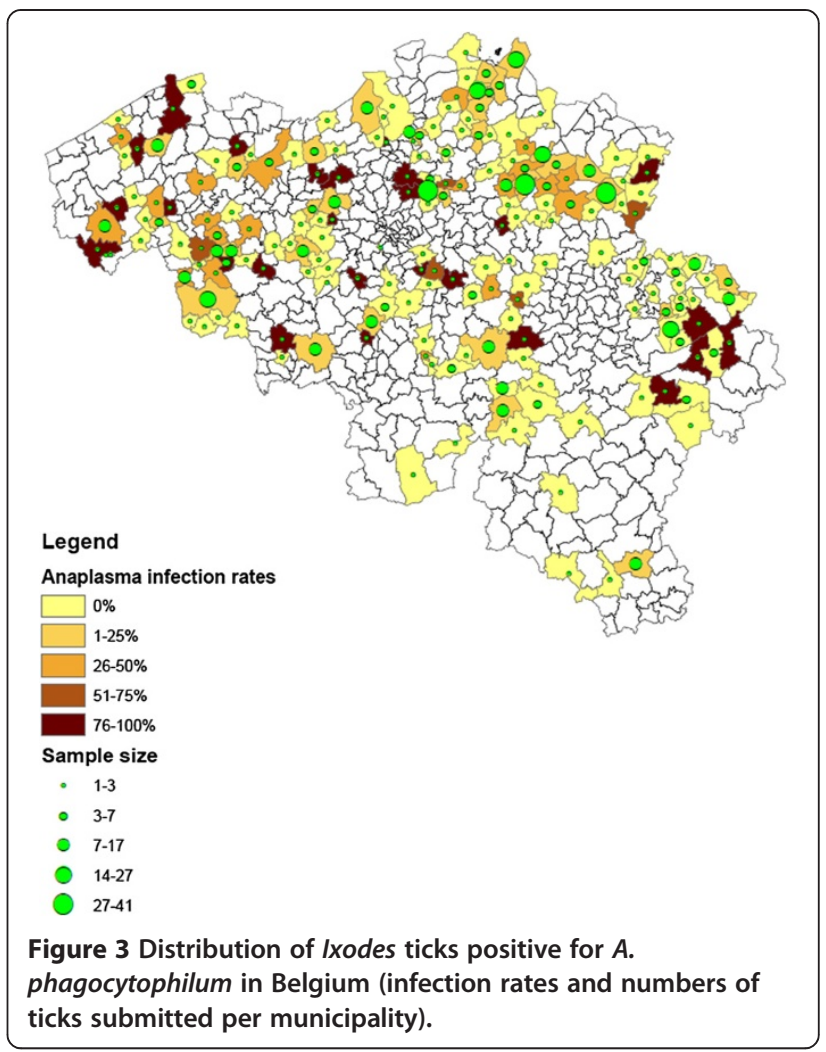

contained A. phagocytophilum DNA, showed either local swelling or inflammation at the site of tick collection ( $\mathrm{n}=4$, one co-infection with Borrelia), lameness $(\mathrm{n}=1)$ or weight loss $(n=1)$. One dog with a Rickettsia-positive tick had arthritis. However, 13 cats and 16 dogs also showed clinical signs that have been associated with tick-borne diseases, such as acute malaise (apathy, fever, anorexia), lameness, lymphadenopathy, glomerulonephritis or neurological signs, while collected ticks were negative for all investigated pathogens. There was no significant difference in the detection rates of B. burgdorferi s.l. $\left(\chi^{2}=2.31\right.$, d.f. $=$ $1, \mathrm{P}=0.13)$, A. phagocytophilum ( $2=0.13$, d.f. $=1, \mathrm{P}=$ 0.72 ) or $R$. helvetica ( $\mathrm{X}^{2}=3.53$, d.f. $=1, \mathrm{P}=0.60$ ) between ticks collected from animals with or without clinical signs.

\section{Discussion}

In this study $I$. ricinus was the predominant tick species infesting companion animals, followed by the hedgehog tick, I. hexagonus. This is in analogy with other studies in North-Western Europe. Similar results were reported from The Netherlands [3], Germany [16] and the UK $[17,18]$. In the UK and Ireland, the fox tick I. canisuga was also frequently recovered from dogs $[17,18]$. Ogden et al. [17] found I. ricinus on a significantly higher proportion of dogs than cats, while I. hexagonus was more frequently found on cats. They suggested that differences in behaviour between dogs and cats could affect their likelihood of encountering both Ixodes species. This 


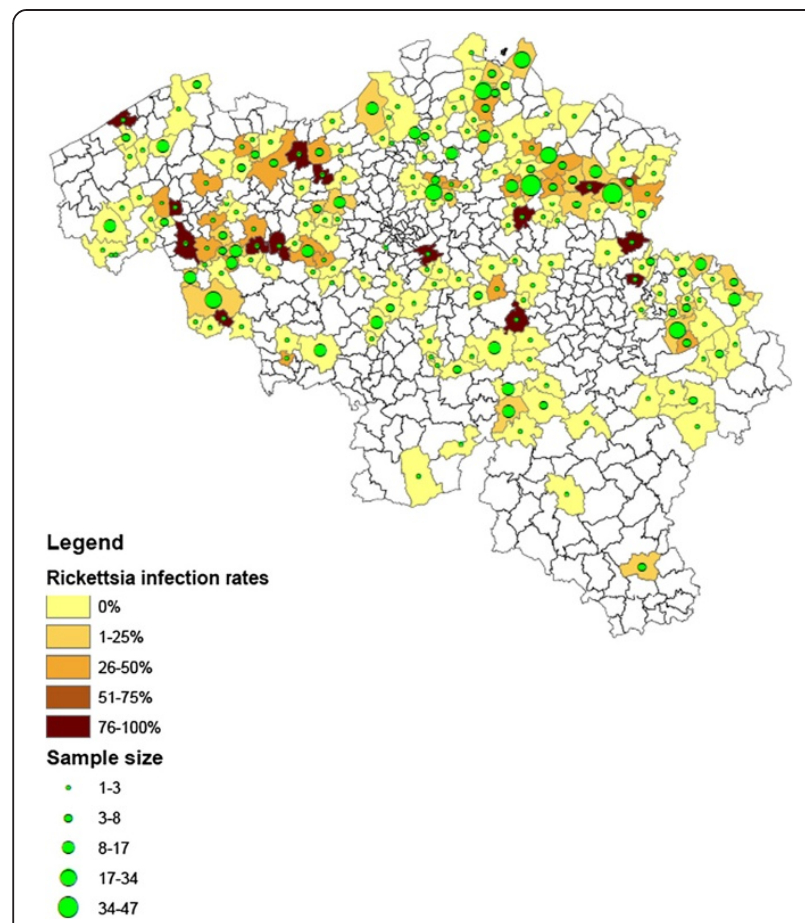

Figure 4 Distribution of Ixodes ticks positive for $R$. helvetica in Belgium (infection rates and numbers of ticks submitted per municipality).

hypothesis was not supported by our data, with similar proportions of dogs and cats carrying $I$. ricinus and $I$. hexagonus. Equal proportions of both Ixodes species were also recovered from dogs and cats in Germany [16] and The Netherlands [3]. The recovered Ixodes ticks were mainly adults, as was also observed in other studies in dogs and cats $[16,18,19]$. Although it cannot be excluded that some nymphs and larvae were overlooked in the clinical inspections, adult Ixodes ticks are known to attach preferably to large or medium-sized mammals, including dogs and cats [20].

Generally, nymphs and adults of $I$. ricinus show a marked seasonal variability in their questing activity, with a first peak in late spring and early summer and a second peak in autumn [21,22]. This seasonal pattern was also observed in the number of ticks recovered from

Table 2 Number of $I$. ricinus and $I$. hexagonus ticks positive and negative for A. phagocytophilum, Borrelia spp. and Rickettsia spp

\begin{tabular}{lccc}
\hline & Ixodes ricinus & Ixodes hexagonus & Total \\
\hline A. phagocytophilum pos & 127 & 37 & 164 \\
A. phagocytophilum neg & 541 & 138 & 679 \\
Borrelia pos & 83 & 14 & 97 \\
Borrelia neg & 662 & 190 & 852 \\
Rickettsia pos & 100 & 32 & 132 \\
Rickettsia neg & 634 & 169 & 803 \\
\hline
\end{tabular}

dogs by [18] and [19]. In this study, we observed an obvious spring peak, but only low numbers of I. ricinus were submitted in autumn. Although participation rates of the veterinarians may have introduced a bias, tick questing activity may be variable from year to year and a single spring or summer peak has previously been observed for questing I. ricinus nymphs [23] and for adult I. ricinus on dogs [16]. Most I. hexagonus were also recovered in the spring in our study, but a second, smaller peak occurred in October. Only limited published information is available on the seasonal abundance of $I$. hexagonus ticks, but seasonal fluctuations in numbers of $I$. hexagonus collected from dogs and hedgehogs are generally weaker compared to I. ricinus $[16,24]$.

The majority of infected ticks were found in Northern Belgium (Flanders). The north-eastern part of Belgium (the Campine) is known to be heavily infested with Ixodes and has a relatively high incidence of Lyme borreliosis [25]. Although the south-eastern part of Belgium has a lot of forest and would also be expected to have a lot of good Ixodes habitats, the number of ticks positive for tick-borne diseases from that area was lower in our study. The reason for this remains unclear.

There was no significant difference between I. ricinus and $I$. hexagonus in the proportion of ticks that contained DNA from B. burgdorferi s.l., A. phagocytophilum or $R$. helvetica. Although both I. ricinus and I. hexagonus can be vectors of Borrelia spp. and A. phagocytophilum [26,27], I. ricinus is considered to be the principal vector of these pathogens $[27,28]$. As a nest dwelling species, I. hexagonus will have little direct contact with humans. Nevertheless, I. hexagonus could be a vector for the transmission of Borrelia spp. and A. phagocytophilum to hedgehogs, and then via co-infections with $I$. ricinus indirectly to humans [24,27].

The percentage of ticks positive for Borrelia spp. was within the range of infection rates $(2.3-22 \%)$ in ticks collected from dogs in other European countries [3,16,29-31]. Similar infection rates were also reported in questing I. ricinus in Belgium (12-23\%) [32,33]. Within the B. burgdorferi sensu lato group, B. afzelii and B. garinii are the most common species in The Netherlands, Belgium and northern France, while B. burgdorferi s.s. is less common in this region [34]. B. valaisiana has also been repeatedly found in The Netherlands (e.g. 3, 29). Together with other recent studies in Belgium and Luxembourg [33,35] our results show that besides $B$. valaisiana, B. spielmanii and B. lusitaniae are also present in Ixodes in the Benelux region. B. garinii, B. afzelii and B. burgdorferi s.s. are well known to be pathogenic for humans, but the pathogenic significance of the other species is still unclear [36,37].

The majority of dogs and cats that are exposed to Borrelia infections remain clinically normal [20], which 
was also the case in this study. Most cases of canine Lyme borreliosis are associated with B. burgdorferi s.s. Whilst B. burgdorferi s.s. is the only Borrelia species in the USA, prevalences of B. burgdorferi s.s. in Europe are much lower [34], as was also the case in this study. This may explain why lyme borreliosis is frequently diagnosed in dogs in endemic regions in the USA, but less frequently in European dogs.

Although Borrelia can be transmitted from dogs to ticks, dogs are not considered as important reservoir hosts [20] and studies examining seropositivity in dogs, their owners and other local residents found no correlation between dog ownership and infection risk [38-40]. Nevertheless, dogs and cats can be used as sentinels for lyme borreliosis. Serological studies in the USA showed that exposure of dogs to B. burgdorferi mimics the geographical distribution of reports of Lyme borreliosis in humans [20] and the use of dog sera to detect and quantify the risk of Lyme borreliosis for humans in a certain region is considered to be more sensitive than the use of incidence reports of human clinical cases [40]. Seroprevalence has been found greater in dogs than in humans due to their greater habitat exposure, lack of protective clothing and inability to check themselves from ticks [38]. The use of dog sera also has the advantage over human serology that the seroprevalence among dogs is more likely to reflect the actual environmental risk of Lyme borreliosis, because of the short half-life of canine antibodies against B. burgdorferi [40]. However, serological studies are often limited by small sample sizes, and false positive results are possible. Detection of Borrelia DNA in ticks collected from dogs and cats can be a valuable alternative [31].

The A. phagocytophilum infection rate in this study was much higher than previously reported point prevalences in Ixodes ticks from dogs in The Netherlands and Poland (1.6-2.9\%) [3,30]. Seroprevalences in dogs in Europe are also very variable, with prevalences from < $5 \%$ to $>50 \%$ [41]. The percentage of seropositive dogs depends on the dog population sampled (e.g. healthy dogs vs. dogs with signs of tick-borne diseases) and geographical variation in exposure to ticks and reservoir hosts. The high infection rate of $A$. phagocytophilum in ticks collected from dogs in this study is in contrast with the low incidence of human granulocytic anaplasmosis (HGA) in Belgium (<100/year) [25]. However, there is a discrepancy between the official (low) incidence rates [25] and the high number of HGA cases that are detected in specific surveys [42,43]. In a recent 10-year serological survey in patients with symptoms of tickborne infections, $31 \%$ of the samples were positive, and 111 cases of HGA were confirmed [42]. These data suggest that Belgium is a hot spot for HGA and that many cases of HGA probably remain undiagnosed [43].
Most dogs infected with $A$. phagocytophilum probably remain healthy [41]. The most common clinical signs in dogs that develop illness are lethargy, fever and lameness. In the present study, no association was found between clinical signs and the presence of $A$. phagocytophilum in ticks collected from these animals. Although identical $16 \mathrm{~S}$ rRNA gene sequences have been found in canine and human isolates of A. phagocytophilum in Europe [44,45], dogs are not thought to be important reservoirs for $A$. phagocytophilum, since bacteremia is of short duration in this species [46]. In Slovenia, no difference in seroprevalence was observed between people with or without exposure to dogs [47].

Ixodes spp. can transmit several Rickettsia species belonging to the 'spotted fever' group, such as Rickettsia helvetica and $R$. monacensis. We found $R$. helvetica DNA in $14.1 \%$ of Ixodes ticks collected from dogs and cats in Belgium. In the Netherlands, 24.7\% I. ricinus ticks and $0.8 \% I$. hexagonus ticks collected from dogs, cats and a hedgehog were infected with $R$. helvetica [3]. In Switzerland, $40.9 \%$ and $17.6 \%$ of Ixodes ticks collected from cats and dogs, respectively, tested positive for $R$. helvetica with a gltA-specific TaqMan PCR system [48]. $R$. helvetica is a suspected pathogen in humans. Symptoms that have been associated with $R$. helvetica infections include fever, headache, arthralgia, myalgia and perimyocarditis [48]. The high prevalence of $R$. helvetica in Ixodes spp. and the high abundance of these tick species suggest that the likelihood of transmission of $R$. helvetica to humans should be high [48]. However, despite a high infection rate (19\%) of $R$. helvetica in ticks collected from humans in the Netherlands, no association between symptoms and $R$. helvetica was found [49].

The clinical importance of $R$. helvetica in domestic animals is as yet uncertain and it is also unknown whether dogs and cats can serve as a reservoir after infection. The fact that the estimated prevalence of $R$. helvetica in ticks collected from dogs, cats and roe deer was higher than in ticks collected from the vegetation $[48,50]$ may indicate that large animals act as a reservoir for $R$. helvetica [48].

Next to $I$. ricinus and $I$. hexagonus, small numbers of $R$. sanguineus and D. reticulatus were collected from dogs. All submitted $R$. sanguineus ticks were considered to be imported, since they were all collected from dogs with a history of travelling abroad, mostly to Southern Europe. One $R$. sanguineus tick contained DNA from $R$. massiliae. $R$. massiliae is suspected to be the main cause of Mediterranean spotted fever in Spain [51].

Although most submitted Dermacentor ticks were also from dogs with a travel history, D. reticulatus ticks were repeatedly sampled from one particular dog that had never been outside Belgium. Flagging confirmed the presence of questing Dermacentor ticks in the area 
where the dog was walked daily [9]. This was the first finding of an indigenous population of $D$. reticulatus in Belgium. Further investigations have revealed the presence of at least 4 other foci of $D$. reticulatus in Belgium (51, M. Madder, unpublished results).

\section{Conclusions}

Repeated collection of $D$. reticulatus from a dog without history of traveling led to the discovery of an indigenous population of D. reticulatus in Belgium [9], confirming the geographical expansion of this tick species in Northwestern Europe. High infection rates were found for Borrelia spp., A. phagocytophilum and R. helvetica in Ixodes ticks collected from dogs and cats in Belgium. B. lusitaniae and $R$. helvetica were detected in ticks in Belgium for the first time.

\section{Abbreviation}

TBEV: Tick-borne encephalitis virus.

\section{Competing interests}

This study was partially financed by Bayer Health Care, Animal Health Division. In the last 5 years, EC has obtained funding from, lectured or consulted for the following companies selling products to treat tick infestations in dogs and cats: Bayer Health Care, Merial, Pfizer Animal Health.

\section{Authors' contributions}

EC conceived of and designed the study, acquired funding, flagged for $D$. reticulatus in Beveren-Waas, conducted data analysis and drafted the manuscript. BL conceived of and designed the study, acquired funding and helped drafting the manuscript. CC and PH performed the real-time PCR analyses for A. phagocytophilum and flagged for D. reticulatus in BeverenWaas. SC developed and performed the PCR analyses for Borrelia, carried out the rapid assay and PCRs for Rickettsia and conducted data analysis. A-CD participated in the design of the study and helped drafting the manuscript. $\mathrm{ADC}$ contributed to the organisation of the study and identified the ticks. MM helped drafting the manuscript and flagged for D. reticulatus in BeverenWaas. CS helped in the design of the study. LL contributed to the organisation of the study, identified the ticks, developed and performed the Babesia PCR, conducted data analysis and helped drafting the manuscript. All authors read and approved the final manuscript.

\section{Acknowledgements \\ Negative and positive control samples for A. phagocytophilum were kindly provided by T. Avsic-Zupanc, University of Ljubljana, Ljubljana, Slovenia. Plasmids containing genomic DNA of Borrelia spp. were kindly provided by F. Jongejan (Utrecht University, The Netherlands) and H. Sprong (RIVM, The Netherlands). N. Mencke (Bayer Health Care) is acknowledged for reviewing the manuscript. The authors are grateful to the participating veterinarians for submitting the ticks.}

\section{Author details \\ 'Laboratory of Parasitology, Faculty of Veterinary Medicine, Ghent University, Merelbeke, Belgium. ${ }^{2}$ Laboratory of Parasitology and Pathology of Parasitic Diseases, University of Liège, Liège, Belgium. ${ }^{3}$ Research Laboratory for Vector Borne Diseases, Queen Astrid Military Hospital, Brussels, Belgium. ${ }^{4}$ Bayer Health Care, Animal Health Division, Diegem, Belgium. ${ }^{5}$ Department of Animal Health Institute of Tropical Medicine, Antwerp, Belgium. ${ }^{6}$ Department of Veterinary Tropical Diseases, Faculty of Veterinary Science, University of Pretoria, Private Bag X04, Onderstepoort, Pretoria 0110, South Africa. ${ }^{7}$ Research Unit of Epidemiology and Risk Analysis Applied to the Veterinary Sciences, University of Liège, Liege, Belgium.}

Received: 3 December 2012 Accepted: 13 June 2013 Published: 19 June 2013

\section{References}

1. Li S, Heyman P, Cochez C, Simons L, Vanwambeke SO: A multi-level analysis of the relationship between environmental factors and questing Ixodes ricinus in Belgium. Parasit Vectors 2012, 5:149.

2. Heile C, Heydorn AO, Schein E: Dermacentor reticulatus (Fabricius, 1794) distribution, biology and vector for Babesia canis in Germany. Berl Munch Tierarztl Wochenschr 2006, 119:330-334.

3. Nijhof AM, Bodaan C, Postigo M, Nieuwenhuijs $H$, Opsteegh $M$ Franssen L, Jebbink F, Jongejan F: Ticks and associated pathogens collected from domestic animals in The Netherlands. Vector Borne Zoonotic Dis 2007, 7:1-11.

4. Dautel H, Dippel C, Oehme R, Hartelt K, Schettler E: Evidence for an increased geographical distribution of Dermacentor reticulatus in Germany and detection of Rickettsia sp. RpA4. Int J Med Microbio/ 2006, 296:149-156.

5. Losson B, Mollet JJ, Avez F, Malaise F, Mignon B: Description de trois cas autochtones de Babésiose canine (Babesia canis) en Belgique. Ann Med Vet 1999, 143:119-124

6. Shaw SE, Day MJ, Birtles RJ, Breitschwerdt EB: Tick-borne infectious diseases of dogs. Trends Parasitol 2001, 17:74-80.

7. Day MJ: One Health: the importance of companion animal vector-borne diseases. Parasit Vectors 2011, 4:49.

8. Dantas-Torres F, Chomel B, Otranto D: Ticks and tick-borne diseases: a One Health perspective. Trends Parasitol 2012, 28:437-446.

9. Cochez C, Lempereur L, Madder M, Claerebout E, Simons L, De Wilde N, Linden A, Saegerman C, Heyman P, Losson B: Foci report of indigenous Dermacentor reticulatus populations in Belgium and a preliminary study on associated babesiosis pathogens. Med Vet Entomol 2012, 26:355-358.

10. Arthur DR: British ticks. London: Butterworth \& Co.; 1963.

11. Boom R, Sol CJ, Salimans MM, Jansen CL, Wertheim-van Dillen PM, Van Der Noordaa J: Rapid and simple method for purification of nucleic acids. J Clin Microbiol 1990, 28:495-503.

12. Baumgarten BU, Rollinghoff M, Bogdan C: Prevalence of Borrelia burgdorferi and granulocytic and monocytic ehrlichiae in Ixodes ricinus ticks from Southern Germany. J Clin Microbiol 1999, 37:3448-3451.

13. Lempereur L, Decat A, Caron Y, Madder M, Claerebout E, Saegerman C, Losson B: First molecular evidence of potentially zoonotic Babesia microti and Babesia sp.EU1 in Ixodes ricinus ticks in Belgium. Vector Borne Zoonotic Dis 2011, 11:125-130.

14. Courtney JW, Kostelnik LM, Zeidner NS, Massung RF: Multiplex real-time PCR for detection of Anaplasma phagocytophilum and Borrelia burgdorferi. J Clin Microbiol 2004, 42:3164-3168.

15. Reis C, Cote M, Paul RE, Bonnet S: Questing ticks in suburban forest are infected by at least six tick-borne pathogens. Vector Borne Zoonotic Dis 2011, 11:907-916.

16. Beichel E, Petney TN, Hassler D, Brückner M, Maiwald M: Tick infestation patterns and prevalence of Borrelia burgdorferi in ticks collected at a veterinary clinic in Germany. Vet Parasitol 1996, 65:147-155.

17. Ogden NH, Cripps P, Davison CC, Owen G, Parry JM, Timms BJ, Forbes AB: The ixodid tick species attaching to domestic dogs and cats in Great Britain and Ireland. Med Vet Entomol 2000, 14:332-338.

18. Smith FD, Ballantyne R, Morgan ER, Wall R: Prevalence, distribution and risk associated with tick infestation of dogs in Great Britain. Med Vet Entomol 2011, 25:377-384.

19. Földvari G, Farkas R: Ixodid tick species attaching to dogs in Hungary. Vet Parasitol 2005, 129:125-131.

20. Little SE, Heise SR, Blagburn BL, Callister SM, Mead PS: Lyme borreliosis in dogs and humans in the USA. Trends Parasitol 2010, 26:213-218.

21. Gray JS: The development and seasonal activity of the tick Ixodes ricinus: a vector of Lyme borreliosis. Rev Med Vet Entomol 1991, 79:323-333.

22. Randolph SE, Green RM, Hoodless AN, Peacey MF: An empirical quantitative framework for the seasonal population dynamics of the tick Ixodes ricinus. Int J Parasitol 2002, 32:979.

23. Tälleklint $L$, Jaenson TGT: Seasonal variations in density of questing Ixodes ricinus (Acari: Ixodidae) nymphs and prevalence of infection with $B$. burgdorferi sl in south central Sweden. J Med Entomol 1996, 33:592-597.

24. Pfäffle M, Petney T, Skuballa J, Taraschewski H: Comparative population dynamics of a generalist (Ixodes ricinus) and specialist tick (I. hexagonus) species from European hedgehogs. Exp Appl Acarol 2011, 54:151-164.

25. Belgian Scientific Institute for Public Health; 2009. https://www.wiv-isp.be/ epidemio/epinl/plabnl/plabannl/index09.htm. 
26. Toutoungi NL, Gern L: Ability of transovarially and subsequent transstadially infected Ixodes hexagonus ticks to maintain and transmit Borrelia burgdorferi in the laboratory. Exp Appl Acarol 1993, 17:581-586.

27. Skuballa J, Petney TN, Pfäffle M, Taraschewski H: Molecular detection of Anaplasma phagocytophilum in the European hedgehog (Erinaceus europaeus) and its ticks. Vector Borne Zoonotic Dis 2010, 10:1055-1057.

28. Mannelli A, Bertolotti L, Gern L, Gray J: Ecology of Borrelia burgdorferi sensu lato in Europe: transmission dynamics in multi-host systems, influence of molecular processes and effects of climate change. FEMS Microbiol Rev 2012, 36:837-868.

29. Hovius KE, Beijer B, Rijpkema SGT, Bleumink-Pluym NMC, Houwers DJ: Identification of four Borrelia burgdorferi sensu lato species in Ixodes ricinus ticks collected from Dutch dogs. Vet Quart 1998, 20:143-145.

30. Zygner W, Jaros S, Wedrychowicz H: Prevalence of Babesia canis, Borrelia afzelii, and Anaplasma phagocytophilum infection in hard ticks removed from dogs in Warsaw (central Poland). Vet Parasitol 2008, 153:139-142.

31. Smith FD, Ballantyne R, Morgan ER, Wall R: Estimating Lyme disease risk using pet dogs as sentinels. Comp Immunol Microb 2012, 35:163-167.

32. Misonne M-C, Van Impe G, Hoet PP: Genetic heterogeneity of Borrelia burgdorferi sensu lato in Ixodes ricinus ticks collected in Belgium. J Clin Microbiol 1998, 36:3352-3354

33. Kesteman T, Rossi C, Bastien P, Brouillard J, Avesani V, Olive N, Martin P, Delmée M: Prevalence and genetic heterogeneity of Borrelia burgdorferi sensu lato in Ixodes ticks in Belgium. Acta Clin Belg 2010, 65:319-322.

34. Rauter C, Hartung T: Prevalence of Borrelia burgdorferi sensu lato genospecies in Ixodes ricinus ticks in Europe: a metaanalysis. App/ Environ Microbiol 2005, 71:7203-7216.

35. Reye AL, Hübschen JM, Sausy A, Muller CP: Prevalence and seasonality of tick-borne pathogens in questing Ixodes ricinus ticks from Luxembourg. Appl Environ Microbiol 2010, 76:2923-2931.

36. Stanek G, Reiter M: The expanding Lyme Borrelia complex - clinical significance of genomic species? Clin Microbiol Infec 2011, 17:487-493.

37. Rudenko N, Golovchenko M, Grubhoffer L, Oliver JH Jr: Updates on Borrelia burgdorferi sensu lato complex with respect to public health. Ticks Tickborne Dis 2011, 2:123-128.

38. Eng TR, Wilson ML, Spielman A, Lastavica CC: Greater risk of Borrelia burgdorferi infection in dogs than in people. J Infect Dis 1988, 158:1410-1411.

39. Cimmino MA, Fumarola D: The risk of Borrelia burgdorferi infection is not increased in pet owners. JAMA-J Am Med Assoc 1989, 262:2997-2998.

40. Goossens HAT, Van Den Bogaard AE, Nohlmans MKE: Dogs as sentinels for human Lyme borreliosis in The Netherlands. J Clin Microbiol 2001, 39:844-848.

41. Carrade DD, Foley JE, Borjesson DL, Sykes JE: Canine granulocytic anaplasmosis: a review. J Vet Intern Med 2009, 23:1129-1141.

42. Cochez C, Ducoffre G, Vandenvelde C, Luyasu V, Heyman P: Human anaplasmosis in Belgium: A 10-year seroepidemiological study. Ticks Tick-borne Dis 2011, 2:156-159.

43. Heyman P, Cochez C, Bigaignon G, Guillaume B, Zizi M, Vandenvelde C: Human granulocytic ehrlichiosis in Belgium: an underestimated cause of disease. J Infect 2003, 47:129-132.

44. Johansson KE, Pettersson B, Uhlen M, Gunnarsson A, Malmqvist M, Olsson E: Identification of the causative agent of granulocytic ehrlichiosis in Swedish dogs and horse by direct solid phase sequencing of PCR products. Res Vet Sci 1995, 58:109-112.

45. Pusterla N, Huder J, Wolfensburger C: Granulocytic ehrlichiosis in two dogs in Switzerland. J Clin Microbiol 1997, 35:2307-2309.

46. Bakken JS, Dumler S: Human granulocytic anaplasmosis. Infect Dis Clin North Am 2008, 22:433-448.

47. Skerget M, Wenisch C, Daxboeck F, Krause R, Haberl R, Stuenzner D: Cat or dog ownership and seroprevalence of ehrlichiosis, Q fever, and cat scratch disease. Emerg Infect Dis 2003, 9:1337-1340.

48. Boretti FS, Perreten A, Meli ML, Cattori V, Willi B, Wengi N, Hornok S, Honegger H, Hegglin D, Woelfel R, Reusch CE, Lutz H, Hofmann-Lehmann R: Molecular investigations of Rickettsia helvetica infections in dogs, foxes, humans and Ixodes ticks. Appl Environ Microbiol 2009, 75:3230-3237.

49. Tijsse-Klasen E, Jacobs JJ, Swart A, Fonville M, Reimerink JH, Brandenburg $\mathrm{AH}$, Van Der Giessen JWB, Hofhuis A, Sprong H: Small risk of developing symptomatic tick-borne diseases following a tick bite in the Netherlands. Parasit Vectors 2011, 4:17.
50. Nielsen H, Fournier PE, Pedersen IS, Krarup H, Ejlertsen T, Raoult D: Serological and molecular evidence of Rickettsia helvetica in Denmark. Scand J Infect Dis 2004, 36:559-563.

51. Fernández-Soto P, Pérez-Sánchez R, Díaz Martín V, Encinas-Grandes A, Sanz Á: Rickettsia massiliae in ticks removed from humans in Castilla y León, Spain. Eur J Clin Microbiol 2006, 25:811-813.

doi:10.1186/1756-3305-6-183

Cite this article as: Claerebout et al:: Ticks and associated pathogens collected from dogs and cats in Belgium. Parasites \& Vectors 2013 6:183.

\section{Submit your next manuscript to BioMed Central and take full advantage of:}

- Convenient online submission

- Thorough peer review

- No space constraints or color figure charges

- Immediate publication on acceptance

- Inclusion in PubMed, CAS, Scopus and Google Scholar

- Research which is freely available for redistribution 